\title{
Segmental Arterial Mediolysis: A Vasculitis Mimic
}

\author{
Saira Bilal ${ }^{1}$ Ayad Alkhatib ${ }^{1} \quad$ E. Blair Solow ${ }^{1}$ Sanjeeva P. Kalva ${ }^{2}$ \\ ${ }^{1}$ Division of Rheumatic Diseases, Department of Internal Medicine, \\ University of Texas Southwestern Medical Center, Dallas, Texas, \\ United States \\ 2Department of Radiology, University of Texas Southwestern \\ Medical Center, Dallas, Texas, United States \\ J Clin Interv Radiol ISVIR 2019;3:151-156
}

\begin{abstract}
Address for correspondence Saira Bilal, MD, Division of Rheumatology, Department of Medicine, George Washington University School of Medicine \& Health Sciences, 2300 M St NM, Washington, DC 20037, United States (e-mail: sbilal@mfa.gwu.edu).
\end{abstract}

\begin{abstract}
Keywords

- vasculitis

- segmental arterial mediolysis

- ANA

Background Segmental arterial mediolysis (SAM) is a rare noninflammatory vasculopathy. The purpose of this report is to describe the clinical data of six patients diagnosed with SAM, discuss key elements for diagnosis, and highlight the differences between SAM and vasculitis. We also propose a modification to the criteria developed by Kalva et al for the diagnosis of SAM.

Methods This is a retrospective study approved by the Institutional Review Board and included patients diagnosed with SAM between January 2008 and December 2016. Eleven patients were identified, of whom six (four males with a median age of 59.5 years) had complete data per the guidelines proposed by Kalva et al and were thus included. Data on patient's clinical presentation, laboratory and imaging findings, and outcomes were collected.

Results Presenting symptoms included abdominal pain, flank pain, and bloody stools. Five patients had negative antinuclear antibodies (ANAs) and one had positive ANAs with negative subserologies. C-reactive protein (CRP) and erythrocyte sedimentation rate (ESR) were normal except for an elevated CRP in two patients with organ infarction. The superior mesenteric and renal arteries were most commonly involved. The most common vascular abnormalities were dissection, pseudoaneurysm, thrombosis, and wall thickening. Two patients received endovascular repair for hepatic artery aneurysms. During the follow-up (range: 3-36 months), two patients developed a new aneurysm or dissection.

Conclusion The long-term prognosis of SAM appears to be favorable. Vascular intervention is only needed for patients with impending vascular compromise. We propose that the criteria developed by Kalva et al could be modified to include patients with elevated ANA but negative subserologies and elevated CRP and ESR in the presence of organ infarction.
\end{abstract}

\section{Introduction}

Segmental arterial mediolysis (SAM) is an uncommon vasculopathy. According to a systematic review, only 101 cases of SAM have been described in the literature between 1976 and 2015. ${ }^{1}$ SAM is noninflammatory, nonatherosclerotic, and nonimmune in origin and involves medium to large vessels. The etiology of SAM is unclear. The disease is characterized by arterial dissections, aneurysm formation, vessel wall thickening, and stenosis, with resultant ischemic and hemorrhagic

received

August 22, 2019

accepted after revision

October 23, 2019

published online

December 4, 2019 manifestations. First described by Slavin and Gonzalez-Vitale in $1976,{ }^{2}$ SAM poses a diagnostic challenge to clinicians and is an important mimicker of inflammatory vasculitis. Kalva et al proposed criteria based on clinical, radiological, and serological findings for the diagnosis of SAM when histopathology is not available. ${ }^{3}$ Radiologists and rheumatologists should be aware of the differences in presentation between vasculitis and SAM. In this report, we describe six cases of SAM diagnosed between 2008 and 2016 at our institution and propose
DOI https://doi.org/

$10.1055 / \mathrm{s}-0039-3401436$

ISSN 2457-0214.
C2019 by Indian Society of

Vascular and Interventional

Radiology
License terms

()(1) $\ominus \circledast$ 
modifications to the criteria suggested by Kalva et al for the diagnosis of SAM.

\section{Methods}

This retrospective study was approved by the Institutional Review Board and performed at a large tertiary institution comprising a 450-bed university academic medical center hospital and a 999-bed county hospital. The requirement to obtain an informed consent for this retrospective study was waived, and the health records of patients included in this study were maintained according to the Health Insurance Portability and Accountability Act (HIPAA). The electronic medical records of these two hospitals were searched for patients with a diagnosis of SAM. There were 11 patients with a diagnosis of SAM during the years 2008 to 2016. The diagnosis of SAM was made using the institutional guidelines proposed by Kalva et al based on clinical, serological, and imaging findings. Five patients were excluded from this study due to incomplete data. The electronic medical records of the remaining six patients were reviewed. Data on patient demographics, clinical presentation, laboratory values, radiological findings on imaging studies, and patient outcomes were extracted.

\section{Results}

\section{Clinical Presentation}

There were four men and two women in our study cohort. The median age at presentation was 59.5 years (range: 40-73 years). The most common presentation was generalized abdominal pain. Patients also reported epigastric pain, intermittent right upper quadrant and lower chest pain, sudden onset unilateral flank and groin pain, bloody stools, and nausea (-Table 1). No constitutional symptoms such as fever, unintentional weight loss, and fatigue were observed prior to or at the time of the presentation. None of the patients reported similar presentations in the past. One patient had a known history of hypertension, and one was found to have factor V Leiden mutation. One patient had a history of methamphetamine use. No known history of autoimmune disease was noted in these patients.

\section{Laboratory Findings}

Five patients had a negative ANA. One patient had a positive ANA; however, all subserologies for systemic autoimmune disease were negative. Inflammatory markers including C-reactive protein (CRP) and erythrocyte sedimentation rate (ESR) were available in all patients. Elevated CRP in two patients was attributed to hepatic and renal infarction. Myeloperoxidase and proteinase 3, which are commonly seen in small vessel vasculitis, were negative in five patients. Hepatitis serologies were available in one patient and were negative in one. Two patients were evaluated by a genetic specialist: one patient had genetic testing and was negative for COL3A1 mutation, and the second patient opted out of genetic testing but was confirmed to not have any clinical features suggestive of Ehlers-Danlos's syndrome.

\section{Imaging Findings}

Imaging studies performed included computed tomography (CT), CT angiography (CTA), magnetic resonance angiography (MRA), and positron emission tomography (PET). Involvement of the superior mesenteric artery $(n=4)(-$ Fig. 2) and the renal artery $(n=4)$ was more common followed by the celiac artery $(n=2)$ and the hepatic artery $(n=2)(-$ Table 1$)$. Dissection, pseudoaneurysm, thrombosis, and vessel wall thickening were common findings on imaging. One patient underwent a PET scan to evaluate the soft tissue surrounding the vessels and to rule out malignancy, which showed no FDG (fluoro-2-deoxy-d-glucose) uptake (-Fig. 1B). In addition, one patient had hepatic infarction, and one patient had renal infarction.

\section{Treatments}

Five patients were treated with aspirin and one with apixaban followed by warfarin. Three patients were treated with antihypertensives. Beta blockers, calcium channel blockers, and angiotensin II receptor blockers were used. One patient developed a new progressively enlarging common hepatic artery aneurysm 3 months after the initial presentation and was treated endovascularly using a flow diverter. Another patient had a large right hepatic artery aneurysm at the time of the presentation in addition to other small aneurysms and vessel dissections. This large aneurysm was considered at a risk of rupture and was treated endovascularly using coil embolization.

\section{Follow-Up}

Follow-up was available in four patients and ranged from 3 to 36 months. Three months after the initial presentation, one patient developed a new common hepatic artery aneurysm (-Fig. 1C, D), as described previously. Six months following endovascular treatment, the aneurysm completely resolved while the hepatic artery patency was maintained. The patient remained asymptomatic. One patient had a complete resolution of symptoms and scarring of renal infarcts and no new lesions during 6 months follow-up. One patient developed a new dissection involving the celiac artery at 3 months follow-up. The celiac artery dissection remained stable, and no new lesions developed at 36 months follow-up. Another patient was followed up for 6 months and showed a resolution of previously seen SMA thrombus.

\section{Discussion}

Segmental arterial mediolysis was originally named segmental mediolytic arteritis. Pathology specimens found noninflammatory lesions as the cause of this disease, and thus it was renamed segmental arterial mediolysis. ${ }^{4}$ The exact etiology of SAM is unknown, and genetic associations for this disease have not been found. ${ }^{5}$ One hypothesis is that repeated vasospasm leads to mediolysis, with arterial wall gaps that lead to arterial dissection and hemorrhage. A reparative phase begins with the formation of granulation tissue. ${ }^{4}$ The responsible pressor agent is considered to be norepinephrine. The excess of norepinephrine and its binding to the $\alpha-1$ 
Table 1 Clinical and imaging findings of six cases

\begin{tabular}{|c|c|c|c|c|c|c|}
\hline Case & $\begin{array}{l}\text { Age (years)/ } \\
\text { sex }\end{array}$ & $\begin{array}{l}\text { Clinical } \\
\text { presentation }\end{array}$ & Imaging findings & Laboratory & Treatments & $\begin{array}{l}\text { Follow-up and } \\
\text { outcomes }\end{array}$ \\
\hline 1 & $61 / M$ & Abdominal pain & $\begin{array}{l}\text { CT of the abdomen: } \\
\text { soft tissue around } \\
\text { the celiac and hepatic } \\
\text { arteries } \\
\text { MRA: arterial narrow- } \\
\text { ing of the hepatic and } \\
\text { celiac arteries } \\
\text { PET: no uptake }\end{array}$ & $\begin{array}{l}\text { Negative ANA } \\
\text { Normal ESR } \\
\text { and CRP }\end{array}$ & $\begin{array}{l}\text { Ticagrelor } \\
\text { Aspirin } \\
\text { Endovascular } \\
\text { therapy for common } \\
\text { hepatic artery } \\
\text { aneurysm }\end{array}$ & $\begin{array}{l}\text { CTA at } 3 \text { mo showed pseu- } \\
\text { doaneurysm of the distal } \\
\text { common hepatic artery }\end{array}$ \\
\hline 2 & $45 / \mathrm{M}$ & $\begin{array}{l}\text { Right flank and } \\
\text { groin pain }\end{array}$ & $\begin{array}{l}\text { MRA: diffuse narrow- } \\
\text { ing of the branches of } \\
\text { the right renal artery } \\
\text { CTA: dissection of the } \\
\text { right renal artery with } \\
\text { renal infarct }\end{array}$ & $\begin{array}{l}\text { Negative } \\
\text { ANA, MPO } \\
\text { antibodies, } \\
\text { PR3 antibod- } \\
\text { ies, and RF } \\
\text { Normal C3 } \\
\text { and C4 } \\
\text { Elevated ESR } \\
\text { and CRP }\end{array}$ & $\begin{array}{l}\text { Aspirin } \\
\text { Carvedilol }\end{array}$ & $\begin{array}{l}\text { CTA at } 6 \text { mo showed no } \\
\text { new aneurysm and scar- } \\
\text { ring of the area of renal } \\
\text { infarct }\end{array}$ \\
\hline 3 & $66 / F$ & $\begin{array}{l}\text { Nausea, vomit- } \\
\text { ing, and bloody } \\
\text { stools }\end{array}$ & $\begin{array}{l}\text { CTA: superior mesen- } \\
\text { teric artery dissection, } \\
\text { partially thrombosed } \\
\text { right and left renal } \\
\text { artery aneurysms }\end{array}$ & $\begin{array}{l}\text { Negative } \\
\text { ANA, dsDNA, } \\
\text { MPO anti- } \\
\text { bodies, PR3 } \\
\text { antibodies, } \\
\text { RF, Jo-1, } \\
\text { Smith, RNP, } \\
\text { Scl-70, SSA, } \\
\text { and SSB } \\
\text { Normal ESR }\end{array}$ & $\begin{array}{l}\text { Aspirin } \\
\text { Losartan } \\
\text { Simvastatin }\end{array}$ & $\begin{array}{l}\text { CTA at } 3 \text { mo consistent } \\
\text { with short segment dis- } \\
\text { section of the celiac artery } \\
\text { Repeat imaging at } 36 \text { mo } \\
\text { showed no new lesions }\end{array}$ \\
\hline 4 & $40 / \mathrm{M}$ & Abdominal pain & $\begin{array}{l}\text { CT: superior mesen- } \\
\text { teric artery dissection }\end{array}$ & $\begin{array}{l}\text { Negative } \\
\text { ANA, MPO } \\
\text { antibodies, } \\
\text { PR3 antibod- } \\
\text { ies, RF, CCP, } \\
\text { Jo-1, Smith, } \\
\text { RNP, Scl-70, } \\
\text { SSA, and SSB. } \\
\text { Normal ESR } \\
\text { and CRP }\end{array}$ & $\begin{array}{l}\text { Aspirin } \\
\text { Metoprolol } \\
\text { Atorvastatin }\end{array}$ & \\
\hline 5 & $73 / F$ & $\begin{array}{l}\text { Right upper } \\
\text { quadrant } \\
\text { abdominal pain, } \\
\text { nausea, and } \\
\text { vomiting }\end{array}$ & $\begin{array}{l}\text { CT: right hepatic lobe } \\
\text { infarct, pseudoaneu- } \\
\text { rysms of the hepatic } \\
\text { artery CTA: multi- } \\
\text { ple hepatic arterial } \\
\text { aneurysms (largest } \\
\text { in the right hepatic } \\
\text { artery and partially } \\
\text { thrombosed) } \\
\text { Catheter angiography: } \\
\text { multiple aneurysms } \\
\text { and dissections in the } \\
\text { celiac and superior } \\
\text { mesenteric artery } \\
\text { branches }\end{array}$ & $\begin{array}{l}\text { Positive ANA } \\
(1: 1280) \\
\text { Negative } \\
\text { dsDNA, MPO } \\
\text { antibodies, } \\
\text { PR3 antibod- } \\
\text { ies, } \\
\text { Jo-1, Smith, } \\
\text { RNP, Scl-70, } \\
\text { SSA, SSB, and } \\
\text { smooth mus- } \\
\text { cle antibody } \\
\text { Elevated CRP }\end{array}$ & $\begin{array}{l}\text { Aspirin } \\
\text { Diltiazem } \\
\text { Coil embolization of } \\
\text { a large pseudoan- } \\
\text { eurysm }(4.7 \times 4 \mathrm{~cm}) \\
\text { originating from the } \\
\text { right hepatic artery }\end{array}$ & \\
\hline 6 & $58 / \mathrm{M}$ & Epigastric pain & $\begin{array}{l}\text { CTA: superior mesen- } \\
\text { teric artery throm- } \\
\text { bosis and dissection, } \\
\text { beaded appearance of } \\
\text { the right renal artery }\end{array}$ & $\begin{array}{l}\text { Negative } \\
\text { ANA, MPO } \\
\text { antibodies, } \\
\text { PR3 anti- } \\
\text { bodies, and } \\
\text { Hepatitis B/C } \\
\text { Elevated CRP }\end{array}$ & Eliquis, warfarin & $\begin{array}{l}\text { CTA at } 6 \text { mo with interval } \\
\text { resolution of thrombus in } \\
\text { the superior mesenteric } \\
\text { artery with persistent } \\
\text { dissection }\end{array}$ \\
\hline
\end{tabular}

Abbreviations: ANA, antinuclear antibody; anti-SSA, anti-sjogren's syndrome A; anti-SSB, anti-sjogren's-syndrome B CCP, anticyclic citrullinated peptide; CRP, C-reactive protein; CTA, CT angiogram; dsDNA, double-stranded DNA; ESR, erythrocyte sedimentation rate; F, female; M, male; MPO, myeloperoxidase; MRA, magnetic resonance angiogram; PET, positron emission tomography; PR3, proteinase 3; RF, rheumatoid factor. 

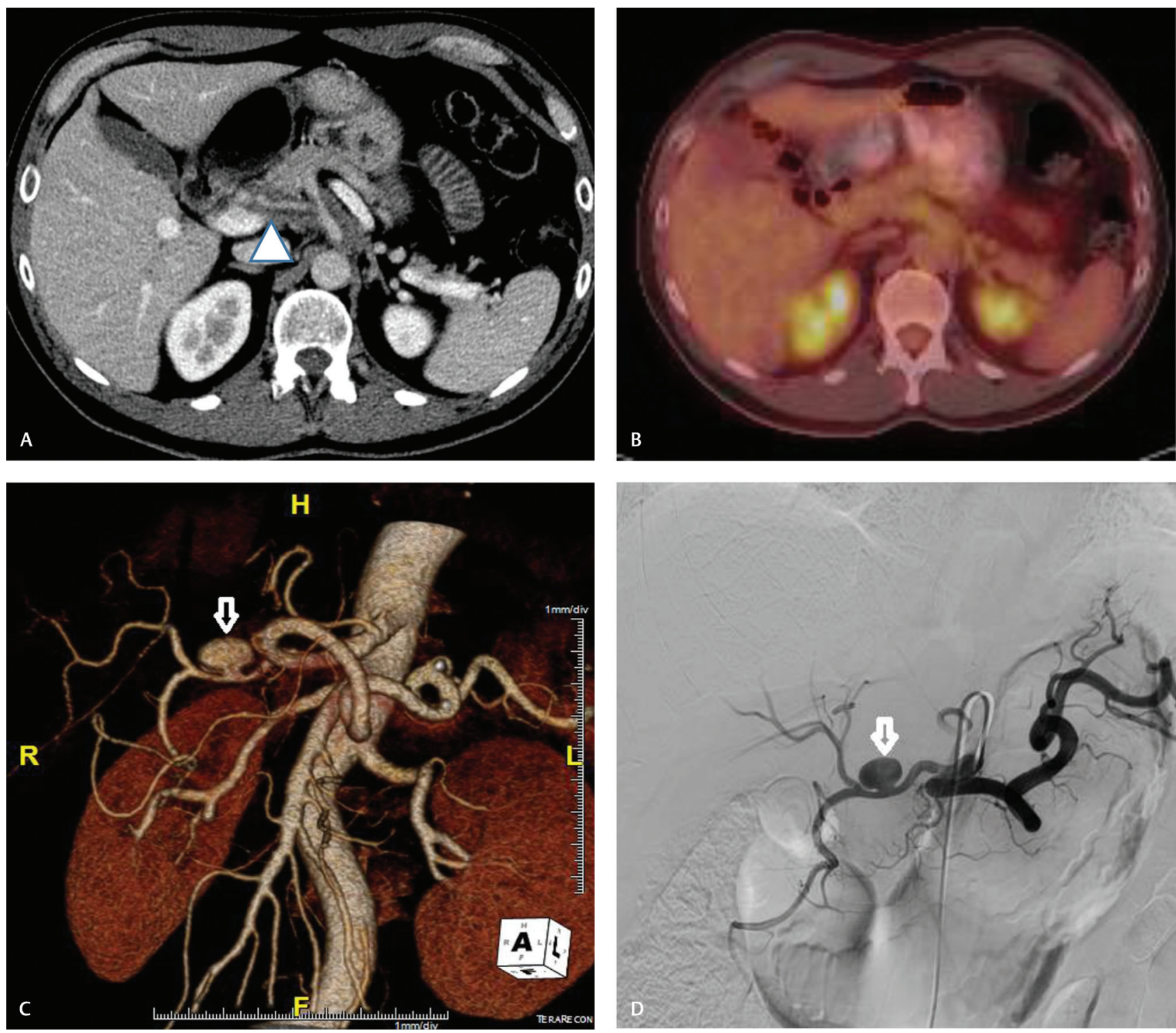

Fig. 1 (A) Contrast-enhanced computed tomography (CT) of the abdomen consistent with soft tissue thickening around the celiac, hepatic, and splenic arteries with irregular lumen of the hepatic artery (arrowhead). (B) PET (positron emission tomography) scan shows no FDG (fluoro-2-deoxy-d-glucose) uptake in the soft tissue thickening around the vessels. Three months later, (C) three-dimensional reconstruction of CT angiography and (D) digital subtraction angiography show the formation of hepatic artery aneurysm (arrow).

adrenergic receptors in the media of the vessel wall was considered responsible for causing vasoconstriction, resulting in shearing of the media from adventitia and creating arterial gaps. ${ }^{6}$ This hypothesis was further strengthened by Slavin and Yaeger who observed vascular changes similar to SAM in greyhound dogs after injecting ractopamine, a $\beta-2$ adrenergic agent. ${ }^{7}$

The vascular bed involved in SAM is similar to that seen in other vasculitides such as polyarteritis nodosa, giant cell arteritis, and Behcet's disease and can pose a diagnostic challenge. SAM has features that are common to those of vasculitis; however, there are clues to prompt the clinician to investigate for other etiologies. Presentation of SAM may range from pain in the involved area, such as abdominal pain, flank pain, and chest pain, to hypertension, stroke, hemorrhage, and hematochezia. Constitutional symptoms such as fatigue, fever, and weight loss that are commonly seen in inflammatory vasculitis are not seen in SAM. Unlike vasculitis, cutaneous involvement such as palpable purpura and ulcers are also not seen in SAM. ${ }^{8}$ Behcet's disease is associated with recurrent oral and genital ulcers and uveitis. Giant cell arteritis may present with headache, visual changes, and jaw claudication and may have associated features of polymyalgia rheumatic with shoulder and hip girdle stiffness. Takayasu arteritis is seen in younger women who can have limb claudication and the absence of pulses. Polyarteritis nodosa may present as skin ulcerations, palpable purpura, livedo reticularis, mononeuritis multiplex, and new-onset hypertension due to renal artery involvement. Vasculitis may also be seen in systemic autoimmune diseases such as systemic lupus erythematosus (SLE) and rheumatoid arthritis; however, patients often will have other features of these diseases such 
as malar rash, oral ulcers, photosensitivity, arthritis, serositis, and glomerulonephritis. Small vessel vasculitis often manifesting as cutaneous vasculitis is seen in SLE, though median and large vessel involvement has also been reported.

The inflammatory markers are usually normal or may be mildly elevated secondary to infarction and hemorrhage in SAM, whereas marked elevation of inflammatory markers is more commonly seen in vasculitis. Other features of chronic inflammation such as anemia can also be seen in vasculitis. Expanded laboratory markers may also aid in differentiating between the two entities. Positive hepatitis B serology may be seen in polyarteritis nodosa, antineutrophilic cytoplasmic antibodies (ANCA) may be seen in ANCA-associated small vessel vasculitis, and positive hepatitis $C$ serology may be seen in cryoglobulinemic vasculitis. Vasculitis associated with systemic autoimmune diseases such as SLE will have additional serologic markers such as a positive ANA, anti-Smith, and dsDNA antibodies. Low complement levels, C3 and C4, are common with autoimmune vasculitis but not with SAM.

Segmental arterial mediolysis typically involves splanchnic vessels, whereas coronary and cerebral involvement is rare. We observed equal involvement of the renal and superior mesenteric arteries in our case series. Arterial dissection with aneurysmal dilation of the false lumen is the hallmark of SAM. Ruptured aneurysm can lead to death. Other imaging features on CT, MRA, or catheter angiography include arterial dilation, single or multiple aneurysms, hematomas, and arterial occlusion, which can lead to end-organ infarction. Intramural hematoma may give the appearance of thickened vessel wall. ${ }^{9}$ It should be noted that vessel wall thickening is also a common imaging finding in vasculitis. Unlike that seen in vasculitis, vessel wall thickening is not associated with wall enhancement in SAM. Similarly, active inflammatory diseases and infiltrative disorders take up FDG on PET scan and appear as hypermetabolic foci. Vessel wall thickening is not FDG-avid in SAM. Multiple aneurysms with intervening intact arterial segments can give the characteristic "string on beads" appearance in SAM. ${ }^{10}$ This appearance may also be seen with fibromuscular dysplasia (FMD). FMD involves the renal artery and is seen more commonly in middle-aged women unlike male predominance of SAM.

Diagnosis of SAM can be obtained by histology; however, considering the location of arterial involvement, a biopsy is not always feasible. Kalva et al proposed institutional guidelines to diagnose SAM on the basis of clinical, laboratory, and imaging findings and by excluding other possible etiologies such as vasculitis and genetic disorders (-Table 2). ${ }^{3}$ The laboratory data in these guidelines required a negative ANA. We propose that the presence of antinuclear antibody (ANA) should not be a limiting factor in the diagnosis of SAM as isolated ANA in the absence of supporting clinical and serological date is not a marker of systemic autoimmune disease. Low titer ANA can be seen in 5\% of the general population without the evidence of autoimmunity, and some studies have reported this prevalence to be as high as $27 \%{ }^{11}$ Clinical significance of ANA is related to the presence of various
Table 2 Institutional guidelines for the diagnosis of segmental arterial mediolysis ${ }^{3}$

\begin{tabular}{|l|l|}
\hline Criteria & Presentation \\
\hline Clinical & $\begin{array}{l}\text { Absence of congenital predisposition for dissections } \\
\text { (e.g., Ehlers-Danlos' syndrome, Marfan's syndrome, } \\
\text { Loeys-Dietz's syndrome) and absence of more } \\
\text { plausible diagnosis such as fibromuscular dysplasia, } \\
\text { collagen vascular disorder, and arteritis }\end{array}$ \\
\hline Acute & $\begin{array}{l}\text { Abdominal or flank pain, back pain, chest pain, acute } \\
\text { hypertension, hypotension, hematuria, or stroke }\end{array}$ \\
\hline Chronic & $\begin{array}{l}\text { Abdominal pain, hypertension, hematuria, no symp- } \\
\text { toms }\end{array}$ \\
\hline Imaging & $\begin{array}{l}\text { Dissection/fusiform aneurysm/occlusion/beaded ap- } \\
\text { pearance/wall thickening of the mesenteric or renal } \\
\text { arteries with or without organ infarction; no associat- } \\
\text { ed contiguous aortic dissection or atherosclerosis }\end{array}$ \\
\hline $\begin{array}{l}\text { Labora- } \\
\text { tory }\end{array}$ & $\begin{array}{l}\text { Absence of inflammatory markers such as antinuclear } \\
\text { antibodies and antineutrophil cytoplasmic antibod- } \\
\text { ies; normal complement levels }\end{array}$ \\
\hline
\end{tabular}

signs and symptoms of autoimmunity such as features of inflammatory arthritis, rash, glomerulonephritis, hemolytic and anemia, and laboratory data such as positive anti-Smith antibody, dsDNA, antiphospholipid antibodies, and low C3 and C4. Thus, an isolated presence of ANA in the absence of other evidence of systemic rheumatic disease should not be considered an exclusion criterion for diagnosing SAM. Similarly, an elevated ESR and CRP may often be observed with organ infarction and should not solely be used to exclude a diagnosis of SAM. ${ }^{12,13}$ Kaneko et al. recently described a rare case of SAM coexisting with scleroderma. ${ }^{14}$

Treatment of SAM includes conservative therapy with antiplatelet therapy, optimal blood pressure control, ${ }^{6}$ and endovascular interventions. ${ }^{5}$ It is paramount for rheumatologists and radiologists to be aware of this important mimicker of vasculitis as the treatment options for these two entities are entirely different. Immunosuppressive therapy is the cornerstone of vasculitis, whereas such therapy is of no value in SAM. SAM lesions may require endovascular therapy, surgical bypass, or resection of the injured vessel. ${ }^{8,15}$ In our case series, one patient required endovascular therapy with a flow diverter, and the second patient required coil embolization of a large pseudoaneurysm. In a recent review, surveillance of eight patients with a median follow-up of 26 months showed the development of new lesions in 50\% of patients. ${ }^{1}$ Two patients in our group developed new lesions in the arteries during follow-up, whereas one patient developed resolution of initial arterial abnormality. Data on follow-up of segmental arterial mediolysis are limited, and thus it is difficult to predict the natural course of the disease.

The diagnosis of SAM and exclusion of vasculitis are based on extensive and meticulous evaluation of the patient's symptoms, preceding events, and laboratory and imaging information, and requires a multidisciplinary approach. A modified Kalva et al criteria will improve the clinician's ability to accurately diagnose segmental arterial mediolysis and further eliminate the possibility of inaccurate diagnosis of vasculitis. 


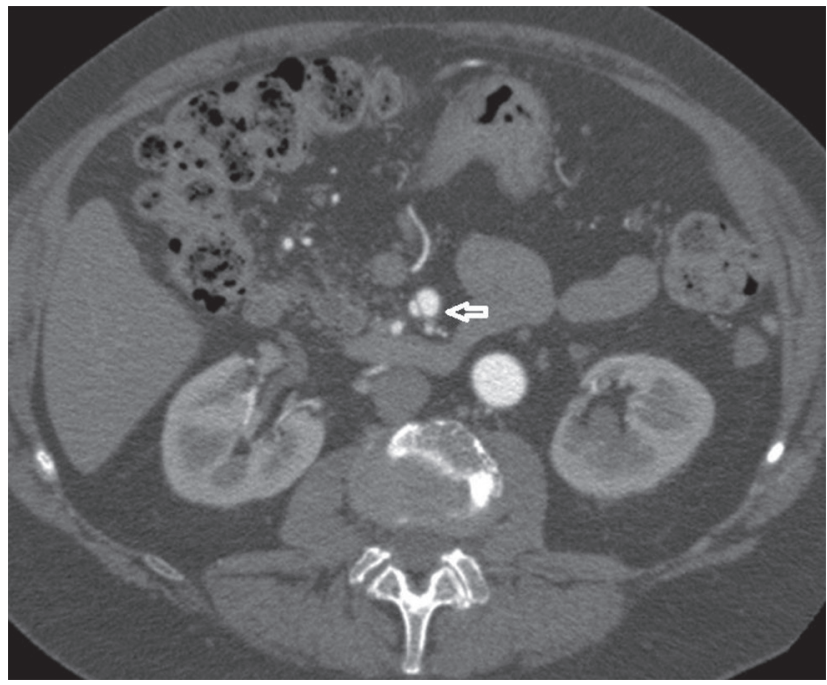

Fig. 2 Contrast -enhanced computed tomography (CT) of the abdomen consistent with superior mesenteric artery dissection (arrow) with pseudoaneurysm.

\section{Author contributions}

S. B. contributed to data collection, data analysis, manuscript drafting, and revisions. A. A. contributed to data collection, data analysis, manuscript revision, and editing. E. B. and S. K. contributed to study design, data analysis, manuscript revision, and editing.

\section{Conflicts of Interest}

Dr. Kalva reports personal fees from Medtronic, Dova Pharmaceuticals, Koo Foundation, Taiwan, GE Healthcare, Springer, and Elsevier, and other from Althea Health Inc., outside the submitted work. He also reports royalties from Elsevier and Springer, consulting fees from General Electric, Medtronic Inc., and Koo Foundation, Taiwan, and research grant from AngioDynamics Inc., and is an investor in Althea Healthcare Inc. Dr. Solow reports grants from the National Institutes of Health (NIH) StopRA study, grants from the Patient-Centered Outcomes Research Institute, grants from NIH SMILE study, nonfinancial support from Janssen CNTOB6 for RA, and nonfinancial support from Pfizer Tofacitinib vs TNF in RA, outside the submitted work.

\section{Acknowledgments}

None.

\section{References}

1 Kim HS, Min SI, Han A, Choi C, Min SK, Ha J. Longitudinal evaluation of segmental arterial mediolysis in splanchnic arteries: case series and systematic review. PLoS One 2016;11(8):e0161182

2 Slavin RE, Gonzalez-Vitale JC. Segmental mediolytic arteritis: a clinical pathologic study. Lab Invest 1976;35(1):23-29

3 Kalva SP, Somarouthu B, Jaff MR, Wicky S. Segmental arterial mediolysis: clinical and imaging features at presentation and during follow-up. J Vasc Interv Radiol 2011;22(10):1380-1387

4 Slavin RE, Saeki K, Bhagavan B, Maas AE. Segmental arterial mediolysis: a precursor to fibromuscular dysplasia? Mod Pathol 1995;8(3):287-294

5 Pillai AK, Iqbal SI, Liu RW, Rachamreddy N, Kalva SP. Segmental arterial mediolysis. Cardiovasc Intervent Radiol 2014;37(3):604-612

6 Slavin RE. Segmental arterial mediolysis: a review of a proposed vascular disease of the peripheral sympathetic nervous system - a density disorder of the alpha-1 adrenergic receptor? J Cardiovasc Dis Diagn 2015;3:190

7 Slavin RE, Yaeger MJ. Segmental arterial mediolysis-an iatrogenic vascular disorder induced by ractopamine. Cardiovasc Pathol 2012;21(4):334-338

8 Baker-LePain JC, Stone DH, Mattis AN, Nakamura MC, Fye KH. Clinical diagnosis of segmental arterial mediolysis: differentiation from vasculitis and other mimics. Arthritis Care Res (Hoboken) 2010;62(11):1655-1660

9 Slavin RE. Segmental arterial mediolysis: course, sequelae, prognosis, and pathologic-radiologic correlation. Cardiovasc Pathol 2009;18(6):352-360

10 Shenouda M, Riga C, Naji Y, Renton S. Segmental arterial mediolysis: a systematic review of 85 cases. Ann Vasc Surg 2014;28(1):269-277

11 Wandstrat AE, Carr-Johnson F, Branch V, et al. Autoantibody profiling to identify individuals at risk for systemic lupus erythematosus. J Autoimmun 2006;27(3):153-160

12 Skeik N, Hyde JR, Olson SL, et al. Nonatherosclerotic abdominal vasculopathies. Ann Vasc Surg 2019;60:128-146

13 Nagamura N, Higuchi H. Segmental arterial mediolysis with preceding symptoms resembling viral infection hampers the differentiation from polyarteritis nodosa. Intern Med 2019;58(18):2721-2726

14 Kaneko S, Watanabe E, Abe M, et al. Scleroderma renal crisis with coexisting segmental arterial mediolysis presenting as intraperitoneal bleeding: a case report. J Med Case Reports 2019;13(1):74

15 Yoshioka T, Araki M, Ariyoshi Y, Wada K, Tanaka N, Nasu Y. Successful microscopic renal autotransplantation for left renal aneurysm associated with segmental arterial mediolysis. J Vasc Surg 2017;66(1):261-264 